\title{
A smart access to global innovation networks
}

\author{
Pascal Magnier \\ CEO Expernova, Cap Oméga, Rond point Benjamin Franklin 34960, Montpellier, France \\ E-mail: pascal.magnier@expernova.com
}

\begin{abstract}
In today's networked age, managing access to expertise is becoming a strategic issue for innovative companies. The digital economy and Big Data are changing the shape of accessing global expertise. Global competition means that large firms can no longer assume that all the expertise they need is available within their own walls, or even within their own countries. To face this growing challenge, organizations of all sizes need a new generation of tools to identify, understand, compare, recommend, and capitalize on their company's networks. By combining impactful data with a collaborative workflow, Expernova helps companies to structure their open innovation processes and access the best expertise worldwide so that they may capitalize on a global network.
\end{abstract}

Keywords: Open innovation, technology scouting, innovation ecosystems, knowledge networks, innovation networks, expert sourcing, network intelligence, supply chain

\section{Leading an open organization}

"The world is becoming too fast, too complex, and too networked for any company to have all the answers inside." ${ }^{1}$ This famous quote perfectly illustrates the context in which innovative companies are operating today. They are forced to confront a new reality:

- The proliferation in the volume of scientific data and the emergence of grey literature;

- The mushrooming of different sources of information, disseminated on a global scale;

- The emergence of highly dynamic new countries and operators;

- The interconnection of many different scientific fields;

- A shortening of product life cycles.

The conclusion is inescapable: keeping informed of the research ecosystem and the scientific and technological environment surrounding an innovative company is becoming increasingly complex and costly. Whether the objective is to pool risks and costs, to seek leverage or to enhance flexibility in order to achieve more rapid commercialization, research partnerships provide a strategic solution.

By the end of 2015, Expernova launched a collaborative and international white paper, integrating testimonies from American and European Innovation leaders. $75 \%$ of surveyed decision-makers said that they engaged in at least one research partnership every year [3].

This survey also underlines the key benefits of transforming its company into an open organization:

- Innovating faster and generating business;

- Benefiting from external know-how;

- Creating value out of in-house expertise;

\footnotetext{
${ }^{1}$ Y. Benkler, The Wealth of Networks: How Social Production Transforms Markets and Freedom, Yale University Press, 2006. ISBN 10:0300125771.
} 
- Pooling risks and costs on innovation projects;

- Anticipating operational needs.

\section{Knowledge networking as a major competitive advantage}

Knowledge is considered as Power. Most organizations' value and competitiveness depend on the development, use and distribution of knowledge-based competencies; so developing powerful knowledge networks is a strategic issue and the most efficient way to access the right expertise at the right moment [6].

Knowledge networking is an effective way of combining individuals' knowledge and skills in the pursuit of company's objectives [5,7]. Knowledge networking is more than access to information because it also delves into the unknown. We are at this time witnessing an evolution of knowledge "consumption," with the emergence of two kinds of experts inside organizations, Knowledge Providers and Knowledge Brokers. Being an expert is not only related to the creation of knowledge during the education process or during the years of academic research or conference speaking experiences, .... It is not only peer recognition... [1,2,4].

In many companies the experts that are the most efficient and considered to be essential are the Knowledge Brokers. They link knowledge providers and operational needs. They do not directly produce knowledge, but they identify and qualify pieces of knowledge and adapt them to a company's strategic focus and projects. Knowledge brokers need to be aware of emerging approaches and techniques with a high-synthesis capacity. These experts determine how the new insights and the existing know-how of the company interact, understanding and exploring different perspectives.

Both Knowledge Providers and Knowledge Brokers need to be part of dynamic networks to gain efficiency. Building powerful Knowledge Networks is both an internal and external task.

Examples of key performance indicators of Knowledge Networks are:

- Openness (out of company's frontiers);

- Global scale;

- Heterogeneity;

- Cross domains/cross industries.

The effectiveness of the actions of an organization will therefore depend on these networks Quality. Organizations have to capitalize on their team's knowledge networks and they are required to manage more and more extended ecosystems, including very different kinds of knowledge or technology providers: academic labs, research institutions, suppliers, Innovative SME, Startups, ... and even competitors. Supply Chain integration for sustainable competitive advantage must now include Knowledge Partnering.

\section{Expernova, a smart access to global expertise}

By combining Impactful Data with a Collaborative Workflow, Expernova helps companies to structure their Open Innovation processes and access the best expertise worldwide to capitalize on a global network.

Gaining a clear vision of the expertise and the global networks allows the organization to answer the most strategic questions more effectively. Who are the people and the key players in our industry with whom we should collaborate? Who are the newcomers to the market? Which ones are developing 
products of interest? What are the other players in my industry working on? My competitors? What are they interested in? (Fig. 1).

Capitalizing, visualizing and developing company's Innovation networks in one place gives the richest insight you'll ever see (Figs 2 and 3).

Expernova's value proposition can be described as "Network Intelligence, for informed Business decisions." Thanks to eight years' experience with key professional interviews and workshops with hundreds of company decision makers, Expernova is a privileged witness to the emergence of these business processes. This allows Expernova to develop a "Best Practices-oriented" solution.

Because each Innovation partner sourcing process is unique, Expernova allows its users to customize their search according their own criteria.

Expernova is the first Business Process Management Solution for leading an Open Organization. The solution is a complete toolkit for knowledge networkers (Open Innovation Managers, R\&D managers, Technology Transfer officers, Competitive Intelligence Analysts, ... ).

- Analytics to take the right decisions;

- Identify, pipeline and engage with partners/experts before competitors;

- Automatic suggestion of relevant potential partners, experts, insights;

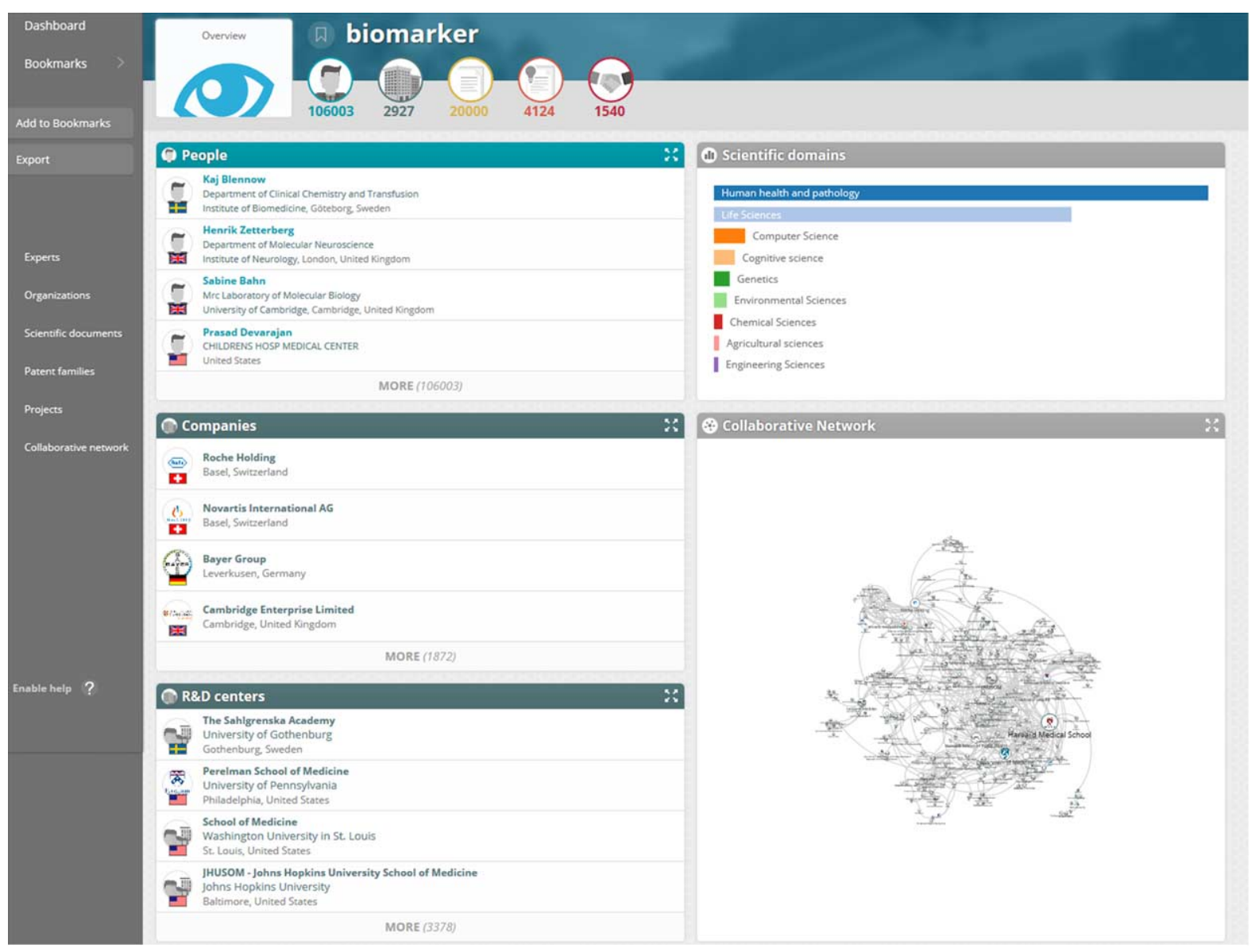

Fig. 1. Visualize an ecosystem in one dashboard. 


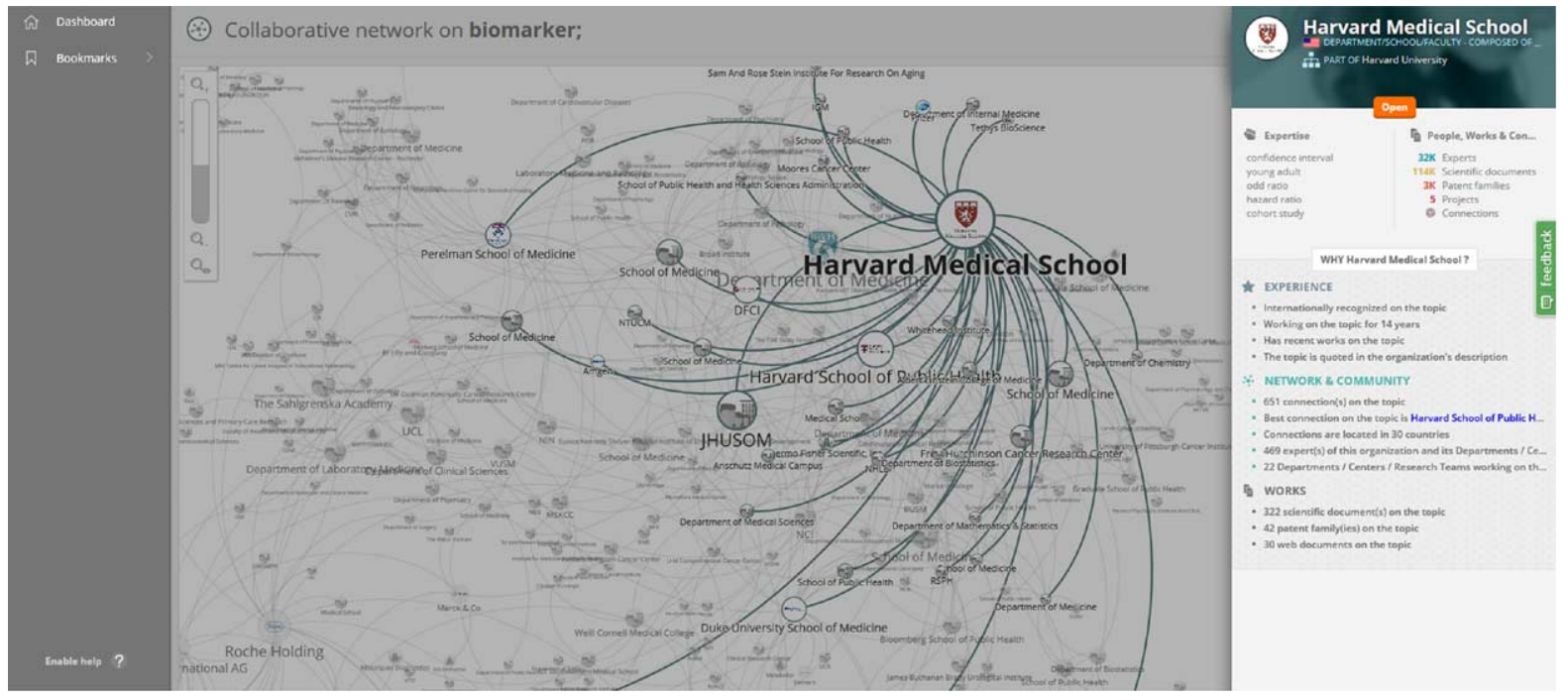

Fig. 2. Understand potential partners skills and dimension.

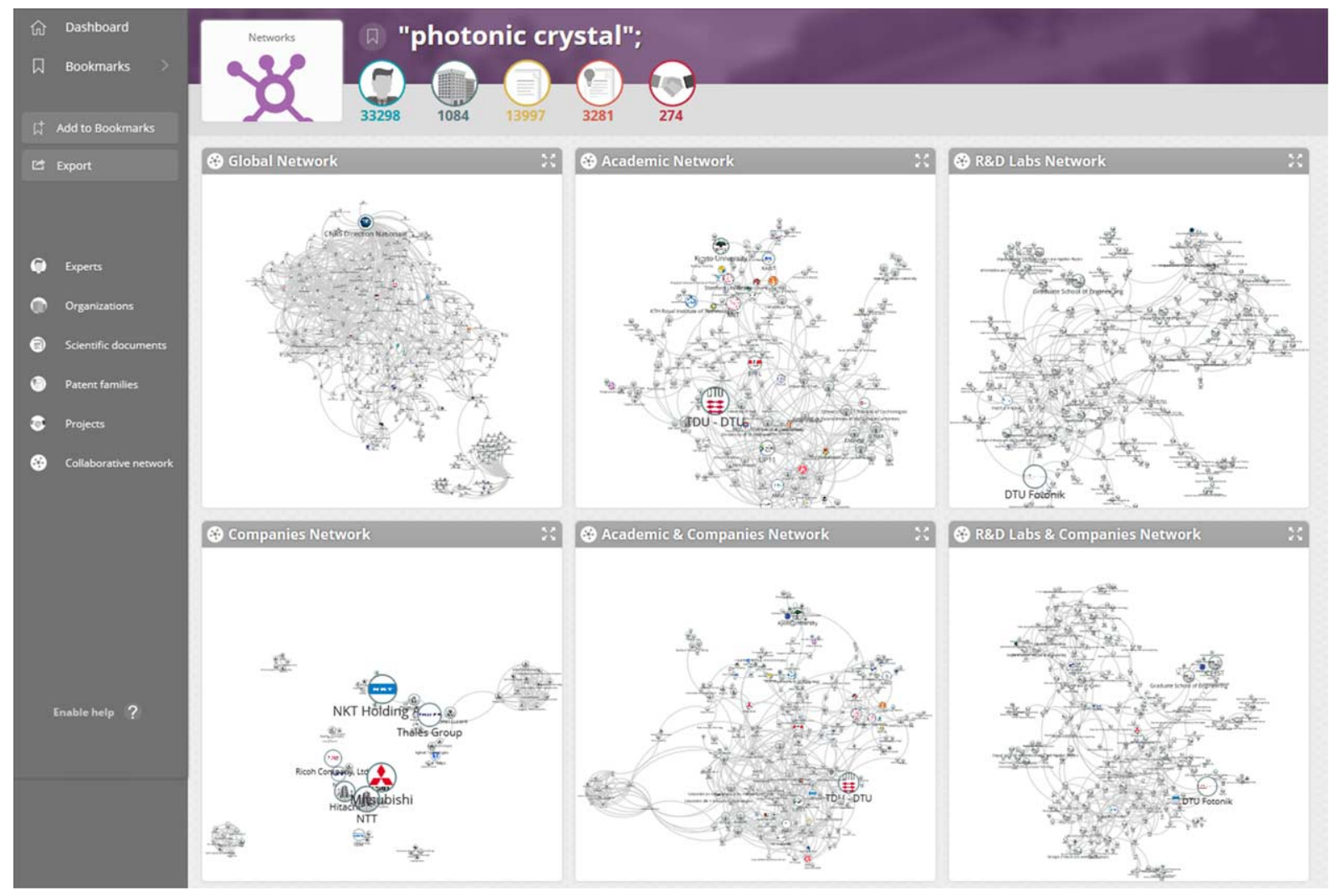

Fig. 3. Explore Innovation Networks to detect Opinion Leaders. 
- Collaborative ecosystem mapping to share knowledge, to train new colleagues, to quickly mobilize the best skills, ....

In a complex environment, Expernova provides a simple solution to make informed decisions, generate new opportunities, and accelerate knowledge and/or technology transfers.

\section{About the author}

Pascal Magnier is the Founder of Expernova, a startup which provides smart access to global expertise. His previous position was "Industrial Performance Manager" for an International Spirit brand. Pascal is an Engineer with a Master's Degree in Business. He is convinced that developing powerful networks is becoming a major competitive differentiator.

\section{References}

[1] B. Cassiman and G. Valentini, Open innovation: Are inbound and outbound knowledge flows really complementary?, Strategic Management Journal 37(6) (2016), 1034-1046. doi:10.1002/smj.2375.

[2] F. Duriez, L'ubérisation de l'expertise, 2016, http://cursus.edu/article/26885/uberisation-expertise/\#.Vyio_ISLS00 (language: French).

[3] Expernova international whitepaper: Leading an Open Organization, October 2015, http://land.expernova.com/ collaborative-white-paper-en-2/.

[4] A. Meige and J.P.M. Schmitt, Vers une uberisation de l'intelligence?, Harvard Business Review, France - 25 août 2015 , http://www.hbrfrance.fr/chroniques-experts/2015/08/8040-vers-une-uberisation-de-lintelligence/ (language: French).

[5] D.J. Skyrme, Knowledge Networking: Creating the Collaborative Enterprise, Elsevier Transferred to Taylor \& Francis as of 2011. ISBN 978-0-7506-3976-7.

[6] The power of networks, MIT Technology Review, November 2013, https://www.technologyreview.com/s/521701/ the-power-of-networks-answer/.

[7] Wikipedia, Knowledge network, https://en.wikipedia.org/wiki/Knowledge_Network. 